\title{
Volumetric brain abnormalities in adolescents with conduct disorder with and without attention deficit-hyperactivity disorder: a case control study
}

\author{
Mohammad A. Seleem ${ }^{1 *}$ D, Rasha El-Shafey², Lamis T. Shahin³, Lina E. Abdel-Aziz³, Noura M. Elkonaisy³, \\ Yomna K. Marey ${ }^{3}$, Mina Rizkallah ${ }^{3}$ and Michael Baghdadi ${ }^{3}$
}

\begin{abstract}
Background: Conduct disorder (CD) is a prevalent psychiatric disorder in youth with heterogeneous presentations and hazardous outcomes on family and society. Identifying potential biological markers may help in better understanding and management of the problem. This work aims to explore the potential volumetric brain abnormalities in an ArabEgyptian sample of conduct disordered youth with and without comorbid ADHD. A total of 27 subjects with conduct disorder, 14 of which also fulfilled the criteria of ADHD, in addition to twenty healthy subjects were recruited. A validated Arabic version of the Mini International Neuropsychiatric Interview for Children and Adolescents "M.I.N.I-Kid" was carried out. MRI acquisition was performed on 1.5 T Toshiba MRI scanner. Cortical reconstruction and automatic volumetric segmentation were performed with the Freesurfer image analysis suite.
\end{abstract}

Results: Youth with CD, with and without ADHD, showed significantly lower cortical thicknesses and smaller subcortical volumes in most of the hemispheric areas. When the two patient groups were compared, youth with CD + ADHD had significantly greater cortical thicknesses but smaller subcortical volumes as compared to youth with CD only.

Conclusions: Conduct disorder, comorbid with ADHD, might prove to be a distinct phenotypic entity with different biological substrates, and hence different needed management, from CD without comorbid ADHD.

Keywords: Conduct, ADHD, Brain, Volumetric

\section{Background}

Conduct disorder $(\mathrm{CD})$ is a prevalent psychiatric disorder characterized by a pattern of disruptive behavior that appears prior to 18 years of age. It includes aggressive tendencies, violence, antisocial behavior, impulsivity, deception, violating the rights of the others, destruction of property, and theft $[7,39]$. Such traits disrupt the child's environment and impair his/her functioning [6]. In combination with general callousness and insensitivity to punishment, these children usually lack the ability to

\footnotetext{
* Correspondence: seleemm@gmail.com; seleemm@med.tanta.edu.eg 'Department of Psychiatry and Neurology, Faculty of Medicine, Tanta University, Elgiesh street, Tanta 31527, Egypt

Full list of author information is available at the end of the article
}

sympathize with others and have poor insight for the emotional impact that their behavior have on others [4, $26]$. The 1-year prevalence of $C D$ was estimated to range between 2 and $10 \%$, with a median of $4 \%$ but incidence is known to rise in adolescence [2]. It has been reported to occur in up to $16 \%$ of otherwise normal preadolescents with higher rates in males as compared to females $[38,39]$. In Egyptian adolescents, The prevalence of conduct disorder was estimated to be as high as $19.5 \%$, with a male to female ratio that ranges from 1.9-2.7:1 [1]. It was estimated that children with severe $\mathrm{CD}$ cost society 10 times more to support into adulthood than those without $\mathrm{CD}[4,53]$. 
Less than $50 \%$ of patients with conduct disorder grow to develop antisocial personality disorder (ASPD) [7, 26] while others develop long-term problems such as anxiety, depression, poor psychosocial functioning, school dropout, unwanted pregnancy, and criminal behavior [4, 26]. Several studies aimed at identifying biological markers that might help in the development of effective predictive, preventive, and therapeutic programs for both conduct and persistent antisocial behavior [18]. Investigated biomarkers include physiological markers [28, 29, 32, 33, 52] and electrophysiological markers $[12,30]$, in addition to alterations in both volumetric and functional brain imaging [45]. So far, results, especially those regarding structural brain imaging in youth with $\mathrm{CD}$, have been inconsistent, with several studies showing decreased and increased grey matter volume in different parts of frontal cortex and limbic system [11, 35, $43,45,56]$. Some other studies failed to report any significant variation in grey matter volume of any brain region in association with disruptive behavior disorders [43].

One of the main suspected causes for the inconsistency in defining potential markers of $\mathrm{CD}$ is the heterogeneity characterizing the CD phenotype itself [18]. Several approaches were suggested to subtype $C D$ according to age at onset $[21,44]$, callous-unemotional traits [17, 19], type of aggression employed (proactive versus instrumental) $[22,23]$, and comorbidity, especially with ADHD [5, 25, 40]. The first two approaches were more studied and included in the Diagnostic and Statistical Manual-5 [2]. More than one approach might be incorporated in one key assumption that inherited impulsivity, one of the main symptoms of ADHD, and interacts across development with social and environmental factors to move across a spectrum that ranges from impulsive, ADHD related, aggression to instrumental aggression, and characteristic for callous-unemotional $\operatorname{CD}[5,8,20]$. The high comorbidity between ADHD and disruptive behavior disorders (oppositional defiant disorder and conduct disorder), which ranges between 35 and 50\%, might add up to the validity of this hypothesis [3, 10, 39].

A recent meta-analysis [45] reviewed twelve structural MRI studies and 17 functional MRI studies in individuals with ODD/CD. Meta-analysis, together with narrative reviews, showed evidence of smaller brain structures and lower brain activity in individuals with ODD/CD regardless of ADHD comorbidity. Reported areas included bilateral amygdala, bilateral insula, right striatum, left medial/superior frontal gyrus, and left precuneus. Another study on youths with CD showed reduced cortical thickness in the superior temporal cortex, in addition to reduced gyrification in the ventromedial frontal cortex, particularly for youths with CD without comorbid ADHD [56]. On the other hand, boys with callous-unemotional conduct problems, as compared with typically developing boys, were reported to have increased grey matter concentration in the medial orbitofrontal and anterior cingulate cortices, as well as increased grey matter volume and concentration in the temporal lobes bilaterally [11]. An inverse association was reported between hyperactive/impulsive symptoms and widespread grey matter abnormalities in the frontoparietal and temporal cortices in children with CD comorbid with ADHD [35].

Both demographic and clinical characteristics of $C D$ are known to be affected by socio-cultural factors which vary widely across cultures and societies [2]. To our knowledge, no previous systematic studies has been done to evaluate youth with CD, ADHD, or both in Arab populations using either structural or functional brain imaging. This work aims to explore the potential volumetric brain abnormalities in an Arab-Egyptian sample of conduct disordered youth with and without comorbid ADHD during late childhood and adolescence.

\section{Methods}

This cross-sectional case-control study was carried out in the child and adolescent inpatient unit in Tanta Psychiatry and Neurology Center, Tanta University, Egypt. All subjects with conduct disorder, with and without comorbid ADHD, admitted to the inpatient unit during a time interval from October 2015 to October 2016 and were invited to participate in the study. Control subjects were recruited among those presenting to the neurology outpatient clinic in the same center for minor neurological complaints, (e.g., headache, nocturnal and enuresis) with no complaint of conduct problems or other psychiatric disorders. Subjects were excluded if they suffer from mental retardation (IQ < 70), schizophrenia, schizo affective, or significant neurological conditions that affect their collaboration with the study. Control subjects were excluded if they have any psychiatric diagnosis on the Mini International Neuropsychiatric Interview for Children and Adolescents "M.I.N. I.-Kid"' and if they have a first degree relative with oppositional defiant disorder, conduct disorder, or ADHD. Participants with contraindications to MRI were also excluded. The total number of adolescents with $\mathrm{CD}$ who were admitted during this time interval was 36 patients, among which 3 patients were excluded because of having IQ lower than 70 and 6 families refused to participate. A total of 27 subjects with conduct disorder, 14 of which also fulfilled the criteria of ADHD, in addition to twenty healthy subjects were recruited to participate in the study.

All procedures performed in studies involving human participants were in accordance with the ethical standards of the institutional research committee and with the 1964 Helsinki declaration and its later amendments or comparable ethical standards. Informed consent was obtained from all individual participants included in the study. All potential hazards were explained to the participants and their families, and all participants gave their 
informed consent before the start of the study. The study was approved by Ethical Research Committee of Faculty of Medicine, Tanta University.

All participants were subjected to full psychiatric history and mental status examination, in addition to physical and neurological examination. Fahmy and El-Sherbini scale [14] was used to collect demographic and socio-economic data for subject and control families. The validated Arabic translation of the Stanford-Binet Intelligence quotient (IQ) fourth edition $[42,55]$ was used to assess the IQ of the participants to determine the general level of intelligence and to exclude subjects with intellectual disability in both patient and control groups. A validated Arabic version of the Mini International Neuropsychiatric Interview for Children and Adolescents "M.I.N.I-Kid" ([24], Sheehan, [13]) was carried out to confirm the diagnosis of $\mathrm{CD}$ and ADHD in subjects with one or both disorders and to exclude any psychiatric diagnoses in participating control subjects. All diagnoses were revised and confirmed by a trained child and adolescent psychiatrist.

MRI acquisition was performed on the $1.5 \mathrm{~T}$ Toshiba MRI scanner (Tokyo, Japan) at Tanta University Hospital. The sequence used was 3D Sagittal T1 FFE3D, with the following scan parameters: slice thickness $=1 \mathrm{~mm}, \mathrm{TR}=$ $7.1 \mathrm{~ms}, \mathrm{TE}=2.9 \mathrm{~ms}$, frequency $=256$, phase $=256$, FOV $=25.6 \mathrm{~cm}$, flip angle $=9^{\circ}, \mathrm{TI}=800 \mathrm{~ms}$, and bandwidth $=$ $220 \mathrm{~Hz} /$ pix. Two 3D T1 weighted images were acquired for each subject for motion correction purposes. Cortical reconstruction and automatic volumetric segmentation were performed with the Freesurfer image analysis suite, version 6.0 (Fig. 1), which is documented and freely available for download online (http://surfer.nmr.mgh.harvard.edu/). Briefly, this processing includes motion correction and averaging of multiple volumetric $\mathrm{T} 1$ weighted images, removal of non-brain tissue using a hybrid watershed/surface deformation procedure, automated Talairach transformation, segmentation of the subcortical white matter, and deep grey matter volumetric structures (including hippocampus, amygdala, caudate, putamen, ventricles). This method uses both intensity and continuity information from the entire three-dimensional MR volumes in segmentation and deformation procedures to produce representations of cortical thickness, calculated as the closest distance from the grey/white boundary to the grey/CSF boundary at each vertex on the tessellated surface. The maps are created using spatial intensity gradients across tissue classes and are therefore not simply reliant on absolute signal intensity. The maps produced are not restricted to the voxel resolution of the original data thus are capable of detecting submillimeter differences between groups [49].

Monte Carlo method for simulation and correction for multiple comparisons was utilized. In order to correct for multiple comparisons, this method depends on performing simulations under the null hypothesis and see how often the value of a statistic from the "true" analysis is exceeded. This frequency is then interpreted as a $p$ value and corrected for multiple comparisons. This is especially useful with surface-based data as traditional random field theory is harder to implement. This simulator is roughly based on FSLs permutation simulator (randomize) and AFNIs null-z simulator (AlphaSim). Note that FreeSurfer
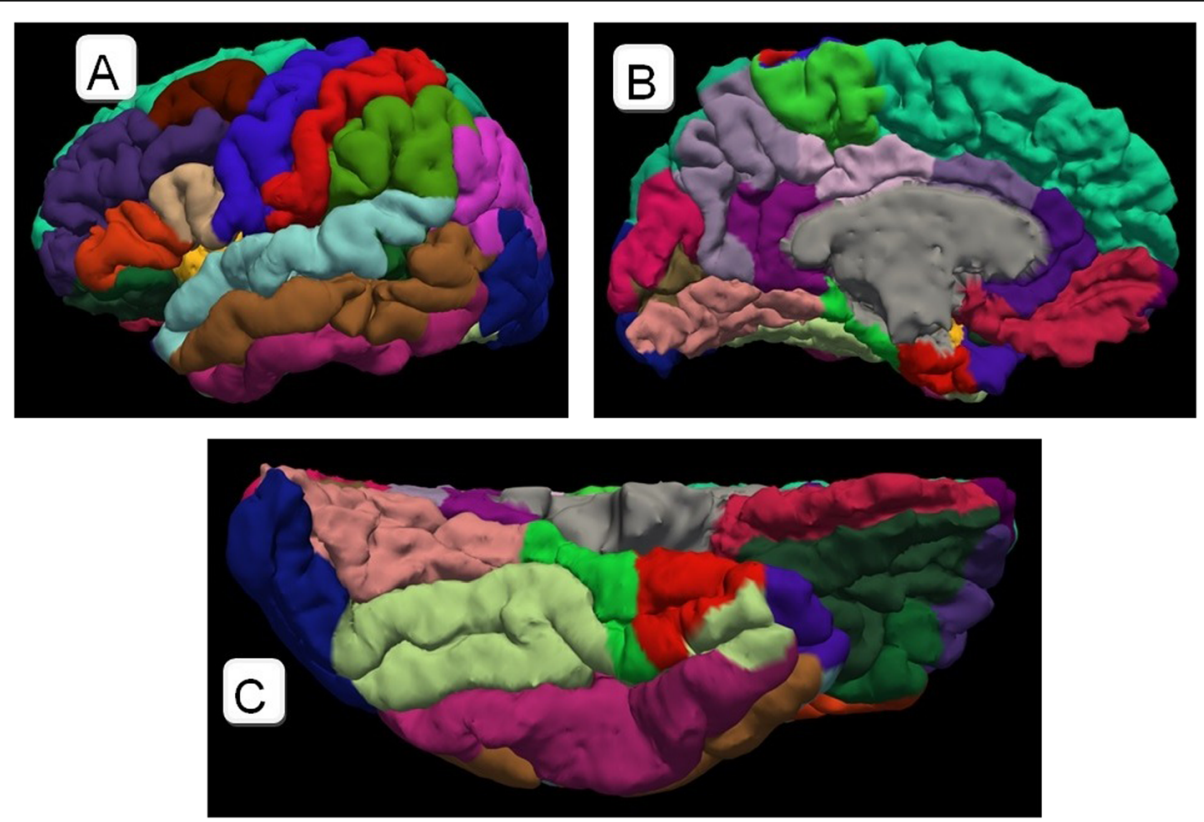

Fig. 1 Brain segmentation. $\boldsymbol{a}$ Lateral view. b Medial view. c Inferior view 
also offers false discovery rate (FDR) correction in tkmedit and tksurfer.

Between-group demographic and clinical characteristics were compared using chi-square, independent $t$ test, oneway ANOVA, and non-parametric analogues (MannWhitney and Fisher's exact tests) as appropriate. All $p$ values were based on two-tailed tests with $a=0.05$. Bonferroni correction was performed as a post-hoc test to evaluate the differences between groups after ANOVA tests. IBM SPSS (Statistical Package for the Social Sciences)-version 19 was used to carry out all analyses.

\section{Results}

A total of 27 subjects with conduct disorder, 14 of which also fulfilled the criteria of ADHD, in addition to twenty healthy subjects were recruited. The sample included 17 female and 30 male subjects. All subjects were $10-18$ years old (mean $13.7 \pm 2.5$ ). The three groups were matched with no significant differences between groups regarding age, sex, socio-economic status, or IQ (Table $1, p \geq 0.05$ ).

First, thickness of frontal cortices in the right hemisphere in the three groups of subjects was calculated (Table 2, Figs. 2,3 , and 4). Apart from the anterior cingulate gyrus which showed no significant differences between the three groups, the $\mathrm{CD}$ only group showed significant reduction in thickness of all estimated frontal areas as compared to the control group. Right hemispheric cortical thicknesses in the control group generally had the greater thicknesses followed by the comorbid (CD + ADHD) group and finally, the $\mathrm{CD}$ only group which showed the least thicknesses in most of the right hemispheric cortical areas. Relatively few areas, e.g., precentral area, lateral orbitofrontal, precentral, and lateral occipital cortices showed significant differences between the two patient groups (i.e., the $\mathrm{CD}$ only and the $\mathrm{CD}+\mathrm{ADHD}$ groups).

Left hemispheres did not show a different pattern (Table 3, Figs. 2, 3, and 4). Frontal areas also showed lower thickness in $\mathrm{CD}$ only, but not in $\mathrm{CD}+\mathrm{ADHD}$, as compared to control group except for the orbitofrontal areas which showed lower thickness in both patient groups as compared to the control group. Thickness in most areas also showed a sloping hierarchy in which control youth had the greatest cortical thicknesses and CD only youth had the lesser ones with the CD + ADHD group in between. The only exception here was caudal middle frontal cortex which showed no significant difference between the three groups. Some other areas showed significant differences between the three groups while other areas showed nonsignificant differences between the CD + ADHD and the control group, e.g., precentral cortex or the $\mathrm{CD}$ only group, e.g., superior temporal and lateral occipital cortices. Another exception from the role of (control $\geq C D+$ $\mathrm{ADHD} \geq \mathrm{CD}$ only) was manifested in the left insula and anterior cingulate cortex which showed a non-significant difference in thickness favoring the $\mathrm{CD}$ only group. Mean cortical thickness in both hemispheres showed significant differences between the three groups with greater thickness in control subjects and lesser thickness in CD only group. The frontal pole and superior frontal cortex in the CD + ADHD group did not show any significant difference with any of the two other groups.

The estimation of the volumes of the subcortical structures did show a quite different pattern (Table 4, Figs. 2, 3 , and 4). Most of the other structures showed smaller volumes in $\mathrm{CD}$ only group as compared to control groups but even smaller volumes in the comorbid (CD + ADHD) group (control $\geq C D$ only $\geq C D+A D H D$ ) with no significant difference between the two patient groups in both amygdale, right hippocampus, or bilateral cerebellar grey, and white matter. The difference between the two patient groups was only significant in left hippocampus which showed lower volume in $\mathrm{CD}+\mathrm{ADHD}$ group when compared to $\mathrm{CD}$ only group. Striatal structures did not generally show significant differences between the three groups on both sides except for the left putamen which showed a greater volume in control which proved significant when compared to $C D$ only and insignificant when compared to $\mathrm{CD}+\mathrm{ADHD}$ group.

\section{Discussion}

When compared to healthy controls, youth with $\mathrm{CD}$, with and without comorbid ADHD, most of the brain areas in the former group showed significantly lower cortical thicknesses and smaller subcortical volumes in comparison to the corresponding areas in the two patient groups except for superior and middle frontal areas which did not show

Table 1 Comparison between adolescents with conduct disorder with and without ADHD together with control adolescents regarding demographic data, socio-economic status, and IQ

\begin{tabular}{|c|c|c|c|c|c|}
\hline Variable & Control subjects $(n=20)$ & Subjects with CD only $(n=13)$ & Subjects with CD and ADHD $(n=14)$ & Statistic & $P$ value \\
\hline Age & $13.7 \pm 2.6$ & $14.8 \pm 1.8$ & $12.9 \pm 2.4$ & $F=2.2$ & 0.12 \\
\hline Sex (female \%) & 45 & 30.8 & 28.6 & $X^{2}=4.3$ & 0.13 \\
\hline SES & $17.3 \pm 5.9$ & $19.2 \pm 5.7$ & $14.6 \pm 5.3$ & $F=3.1$ & 0.11 \\
\hline IQ & $90.1 \pm 11.3$ & $96.5 \pm 8.9$ & $89.3 \pm 5.4$ & $F=3.6$ & 0.09 \\
\hline
\end{tabular}

Comparisons were done using pair-wise chi-square tests for categorical variables and ANOVA test for numerical variables ( $p$ values $\leq 0.05)$

SES socio-economic status according to Fahmi and El-sherbini scale. 
Table 2 Comparison between adolescents with conduct disorder, with and without ADHD, and control adolescents regarding right hemispheric cortical thickness (mm)

\begin{tabular}{|c|c|c|c|c|c|c|c|c|}
\hline \multirow[t]{2}{*}{ Area } & \multicolumn{2}{|c|}{ Control $(n=20)$} & \multicolumn{2}{|c|}{ CD only $(n=13)$} & \multicolumn{2}{|c|}{$\mathrm{ADHD}+\mathrm{CD}(n=14)$} & \multirow[t]{2}{*}{$F$} & \multirow[t]{2}{*}{$p$ value } \\
\hline & Mean & SD & Mean & SD & Mean & SD & & \\
\hline Frontal pole & $2.938^{\mathrm{a}}$ & 0.363 & $2.456^{\mathrm{b}}$ & 0.423 & $2.780^{\mathrm{a}}$ & 0.414 & 5.9 & 0.005 \\
\hline Superior frontal & $2.940^{\mathrm{a}}$ & 0.222 & $2.735^{b}$ & 0.161 & $2.952^{\mathrm{a}}$ & 0.129 & 6.3 & 0.004 \\
\hline Rostral middle frontal & $2.506^{\mathrm{a}}$ & 0.152 & $2.256^{\mathrm{b}}$ & 0.054 & $2.481^{a}$ & 0.243 & 9.7 & $\leq 0.001$ \\
\hline Caudal middle frontal & $2.717^{\mathrm{a}}$ & 0.239 & $2.486^{\mathrm{b}}$ & 0.248 & $2.752^{\mathrm{a}}$ & 0.127 & 6.2 & 0.004 \\
\hline Lateral orbitofrontal & $2.844^{\mathrm{a}}$ & 0.165 & $2.304^{b}$ & 0.141 & $2.563^{c}$ & 0.068 & 63.3 & $\leq 0.001$ \\
\hline Medial orbitofrontal & $2.723^{\mathrm{a}}$ & 0.186 & $2.253^{b}$ & 0.110 & $2.411^{b}$ & 0.327 & 19.1 & $\leq 0.001$ \\
\hline Anterior cingulate & 2.698 & 0.345 & 2.594 & 0.249 & 2.622 & 0.239 & 0.6 & 0.6 \\
\hline Posterior cingulate & $2.787^{a}$ & 0.161 & $2.475^{\mathrm{b}}$ & 0.100 & $2.563^{b}$ & 0.106 & 25.0 & $\leq 0.001$ \\
\hline Precentral & $2.660^{\mathrm{a}}$ & 0.146 & $2.350^{b}$ & 0.166 & $2.514^{c}$ & 0.187 & 14.2 & $\leq 0.001$ \\
\hline Insula & $3.250^{\mathrm{a}}$ & 0.293 & $2.943^{b}$ & 0.213 & $3.060^{a, b}$ & 0.190 & 6.6 & 0.003 \\
\hline Post central & $2.179^{a}$ & 0.140 & $1.915^{\mathrm{b}}$ & 0.183 & $2.022^{\mathrm{b}}$ & 0.128 & 12.9 & $\leq 0.001$ \\
\hline Precuneus & $2.654^{\mathrm{a}}$ & 0.183 & $2.360^{b}$ & 0.112 & $2.502^{b}$ & 0.134 & 15.0 & $\leq 0.001$ \\
\hline Superior temporal & $2.989^{a}$ & 0.267 & $2.575^{b}$ & 0.270 & $2.632^{b}$ & 0.132 & 15.3 & $\leq 0.001$ \\
\hline Lateral occipital & $2.298^{\mathrm{a}}$ & 0.192 & $1.716^{\mathrm{b}}$ & 0.076 & $1.945^{c}$ & 0.154 & 57.6 & $\leq 0.001$ \\
\hline Mean right hemispheric & $2.664^{\mathrm{a}}$ & 0.137 & $2.317^{b}$ & 0.109 & $2.490^{c}$ & 0.103 & 33.4 & $\leq 0.001$ \\
\hline
\end{tabular}

Comparisons were done using ANOVA test for all variables ( $p$ values $\leq 0.05$ )

Different superscripts mean significant difference between groups after Bonferroni correction.

significant differences between the comorbid and the control group. When the two latter groups were compared to each other, youth with CD + ADHD had significantly greater cortical thicknesses but smaller subcortical volumes as compared to youth with CD only. Differences between
$\mathrm{CD}+\mathrm{ADHD}$ and control groups were less consistent in prefrontal areas, especially in the right hemisphere. Another prominent exception was striatal structure which did not show significant differences between the three groups except a weakly significant difference in the left pallidum.

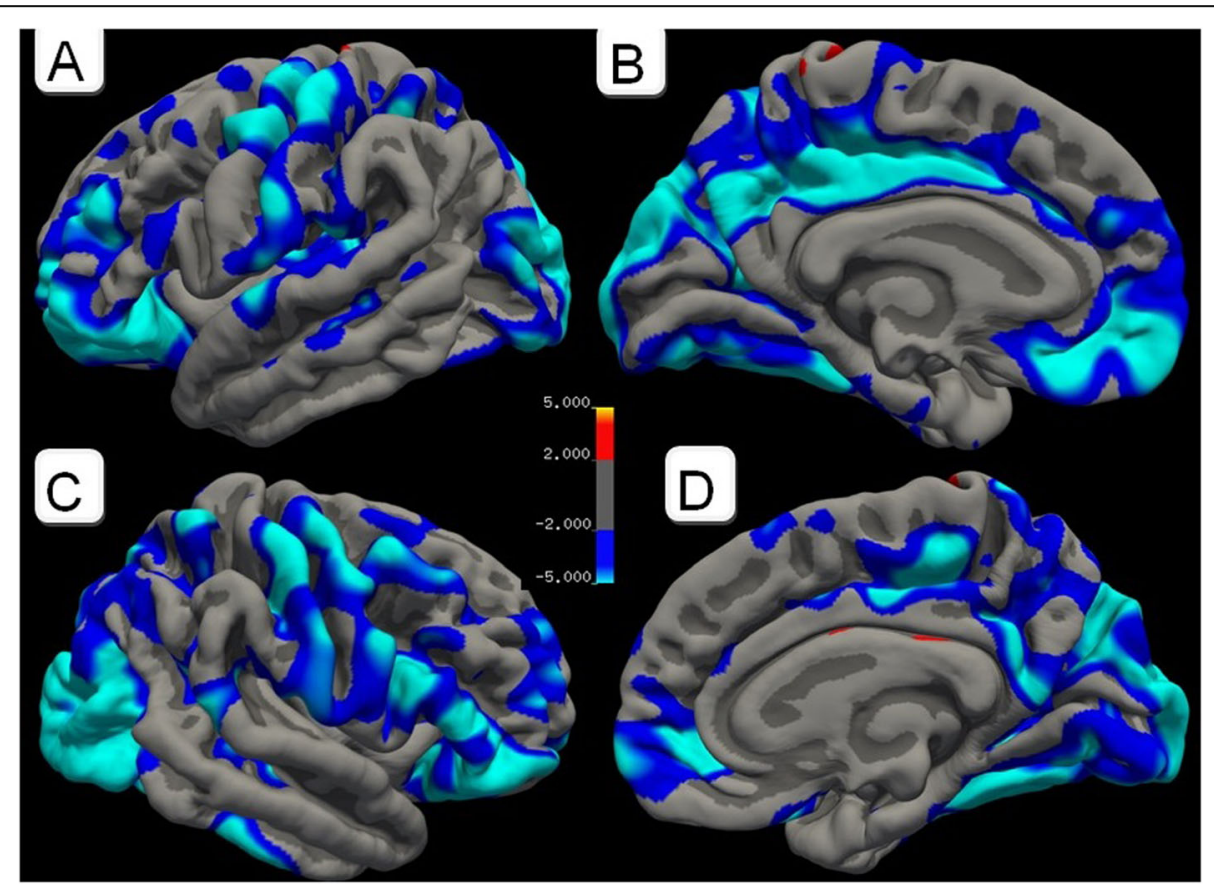

Fig. 2 Brain surface demonstrating significant differences between youth with conduct disorder (CD only) versus healthy control youth. a Left lateral. b Left medial. c Right lateral. d Right medial 

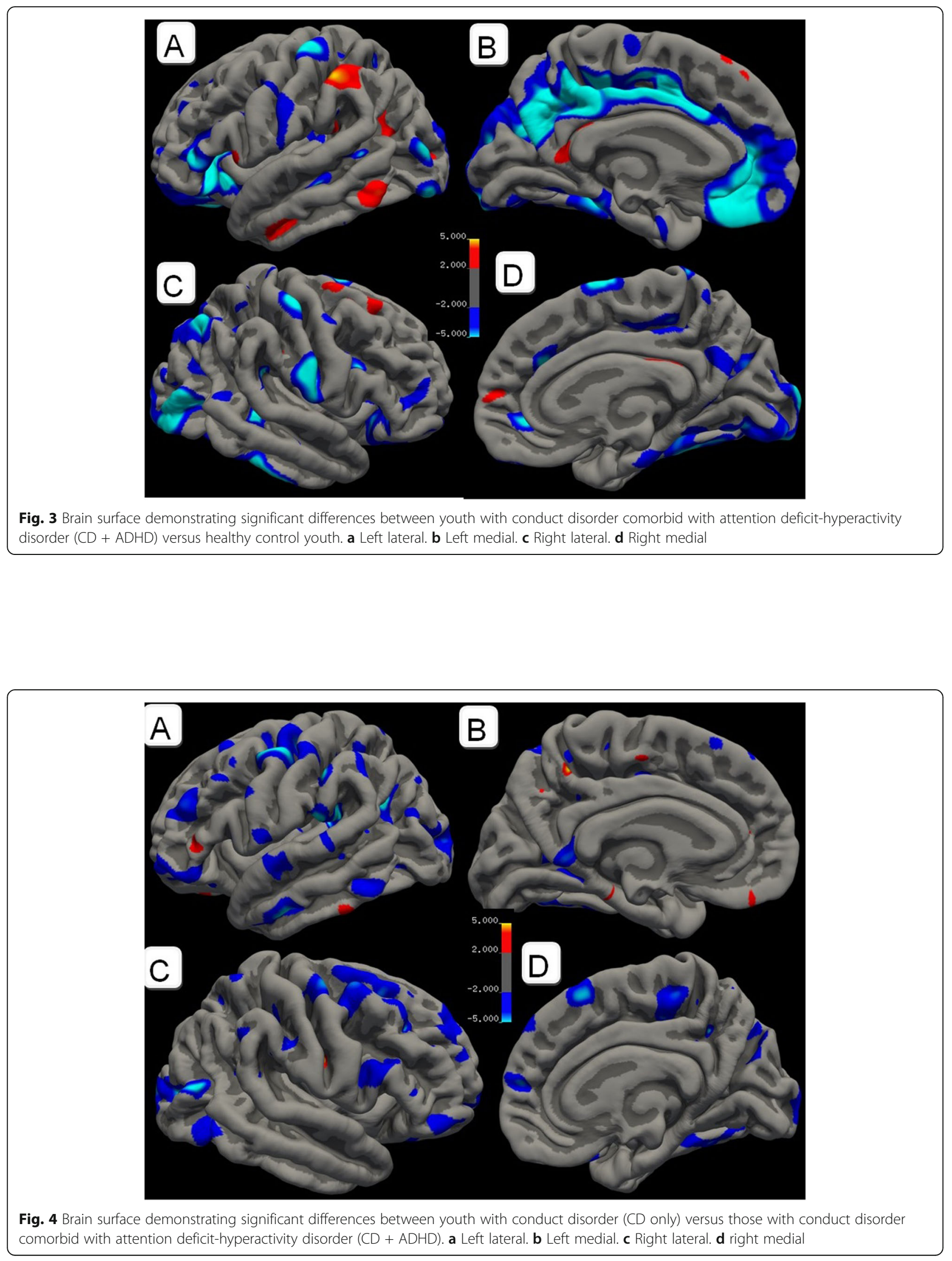
Table 3 Comparison between adolescents with conduct disorder, with and without ADHD, and control adolescents regarding left hemispheric cortical thickness ( $\mathrm{mm}$ )

\begin{tabular}{|c|c|c|c|c|c|c|c|c|}
\hline \multirow{2}{*}{ Area } & \multicolumn{2}{|c|}{ Control $(n=20)$} & \multicolumn{2}{|c|}{ CD only $(n=13)$} & \multicolumn{2}{|c|}{$\mathrm{ADHD}+\mathrm{CD}(n=14)$} & \multirow[t]{2}{*}{$F$} & \multirow[t]{2}{*}{$p$ value } \\
\hline & Mean & SD & Mean & SD & Mean & SD & & \\
\hline Frontal pole & $3.129^{a}$ & 0.387 & $2.587^{b}$ & 0.556 & $2.731^{a, b}$ & 0.537 & 5.7 & 0.007 \\
\hline Superior frontal & $2.980^{a}$ & 0.229 & $2.701^{b}$ & 0.147 & $2.839^{a, b}$ & 0.200 & 7.7 & 0.001 \\
\hline Rostral middle frontal & $2.541^{\mathrm{a}}$ & 0.278 & $2.127^{\mathrm{b}}$ & 0.109 & $2.344^{c}$ & 0.199 & 14.1 & 0.000 \\
\hline Caudal middle frontal & 2.674 & 0.241 & 2.516 & 0.207 & 2.702 & 0.100 & 3.5 & 0.04 \\
\hline Lateral orbitofrontal & $2.920^{a}$ & 0.188 & $2.338^{b}$ & 0.146 & $2.437^{b}$ & 0.162 & 57.3 & $\leq 0.001$ \\
\hline Medial orbitofrontal & $2.694^{a}$ & 0.227 & $2.195^{b}$ & 0.110 & $2.166^{b}$ & 0.245 & 35.2 & $\leq 0.001$ \\
\hline Anterior cingulate & $2.777^{\mathrm{a}}$ & 0.373 & $2.450^{\mathrm{a}, \mathrm{b}}$ & 0.471 & $2.269^{b}$ & 0.391 & 6.8 & 0.003 \\
\hline Posterior cingulate & $2.823^{\mathrm{a}}$ & 0.232 & $2.300^{b}$ & 0.237 & $2.384^{b}$ & 0.286 & 21.4 & $\leq 0.001$ \\
\hline Precentral & $2.705^{a}$ & 0.179 & $2.370^{b}$ & 0.149 & $2.598^{a}$ & 0.117 & 18.6 & $\leq 0.001$ \\
\hline Insula & $3.232^{a}$ & 0.255 & $2.954^{b}$ & 0.287 & $2.939^{b}$ & 0.188 & 7.8 & 0.001 \\
\hline Post central & $2.201^{a}$ & 0.147 & $1.960^{\mathrm{b}}$ & 0.194 & $2.046^{b}$ & 0.153 & 9.3 & $\leq 0.001$ \\
\hline Precuneus & $2.678^{\mathrm{a}}$ & 0.206 & $2.270^{b}$ & 0.158 & $2.315^{b}$ & 0.147 & 27.2 & $\leq 0.001$ \\
\hline Superior temporal & $2.945^{\mathrm{a}}$ & 0.221 & $2.598^{b}$ & 0.096 & $2.786^{\mathrm{C}}$ & 0.113 & 17.5 & $\leq 0.001$ \\
\hline Lateral occipital & $2.267^{\mathrm{a}}$ & 0.169 & $1.874^{\mathrm{b}}$ & 0.094 & $2.073^{c}$ & 0.217 & 21.5 & $\leq 0.001$ \\
\hline Mean left hemispheric & $2.669^{a}$ & 0.144 & $2.348^{b}$ & 0.075 & $2.513^{c}$ & 0.095 & 31.3 & $\leq 0.001$ \\
\hline
\end{tabular}

Comparisons were done using ANOVA test for all variables ( $p$ values $\leq 0.05$ )

Different superscripts mean significant difference between groups after Bonferroni correction.

Before further discussing the results, it is important to highlight the limitations of this study. First, the sample was recruited through an inpatient child psychiatry program, which usually includes severely ill youth. Therefore, the results may not be generalizable to other populations. Second, any influence of any given medication on the results cannot be ruled out. Third, the effect of comorbid disorders, other than ADHD, on estimated variables, cannot be ruled out in both patient groups. Finally, the relatively small number of subjects and using only structural, not functional, imaging techniques both decrease the significance of the current study.

Early studies who performed structural MRI in samples of youth with $\mathrm{CD}$ comorbid with ADHD used

Table 4 Comparison between adolescents with conduct disorder, with and without ADHD, and control adolescents regarding subcortical volumes $\left(\mathrm{cm}^{3}\right)$

\begin{tabular}{|c|c|c|c|c|c|c|c|c|}
\hline \multirow[t]{2}{*}{ Area } & \multicolumn{2}{|c|}{ Control $(n=20)$} & \multicolumn{2}{|c|}{ CD only $(n=13)$} & \multicolumn{2}{|c|}{$\mathrm{ADHD}+\mathrm{CD}(n=14)$} & \multirow[t]{2}{*}{$F$} & \multirow[t]{2}{*}{$p$ value } \\
\hline & Mean & SD & Mean & SD & Mean & SD & & \\
\hline Right putamen & 6.406 & 0.806 & 5.797 & 0.828 & 6.021 & 0.427 & 2.99 & 0.06 \\
\hline Right pallidum & 1.805 & 0.259 & 2.032 & 0.429 & 2.073 & 0.364 & 3.05 & 0.06 \\
\hline Right hippocampus & $4.412^{\mathrm{a}}$ & 0.451 & $3.663^{b}$ & 0.482 & $3.369^{b}$ & 0.631 & 18.43 & $\leq 0.001$ \\
\hline Right amygdala & $1.752^{\mathrm{a}}$ & 0.278 & $1.419^{b}$ & 0.235 & $1.360^{\mathrm{b}}$ & 0.471 & 6.76 & 0.003 \\
\hline Right accumbens nucleus & $0.760^{\mathrm{a}}$ & 0.149 & $0.572^{\mathrm{b}}$ & 0.078 & $0.674^{a, b}$ & 0.053 & 11.63 & $\leq 0.001$ \\
\hline Right cerebellar white matter & $15.331^{\mathrm{a}}$ & 2.602 & $12.658^{\mathrm{b}}$ & 1.221 & $12.528^{b}$ & 0.810 & 12.3 & 0.0001 \\
\hline Right cerebellar grey matter & $59.068^{\mathrm{a}}$ & 6.307 & $51.189^{b}$ & 6.299 & $49.727^{b}$ & 7.366 & 9.9 & 0.0003 \\
\hline Left putamen & $6.513^{a}$ & 0.888 & $5.777^{\mathrm{b}}$ & 0.830 & $6.230^{a, b}$ & 0.308 & 3.84 & 0.03 \\
\hline Left pallidum & 1.951 & 0.365 & 1.810 & 0.319 & 1.971 & 0.271 & 1.00 & 0.4 \\
\hline Left hippocampus & $4.410^{\mathrm{a}}$ & 0.620 & $3.893^{b}$ & 0.429 & $3.287^{c}$ & 0.527 & 17.46 & $\leq 0.001$ \\
\hline Left amygdala & $1.717^{\mathrm{a}}$ & 0.270 & $1.266^{b}$ & 0.150 & $1.162^{b}$ & 0.144 & 34.31 & $\leq 0.001$ \\
\hline Left accumbens nucleus & $6.406^{a}$ & 0.806 & $5.797^{b}$ & 0.828 & $6.021^{a}$ & 0.427 & 6.50 & 0.003 \\
\hline Left cerebellar white matter & $14.784^{\mathrm{a}}$ & 2.388 & $12.587^{\mathrm{b}}$ & 0.992 & $13.076^{\mathrm{b}}$ & 1.400 & 6.8 & 0.003 \\
\hline Left cerebellar grey matter & $58.266^{a}$ & 6.604 & $50.250^{b}$ & 5.710 & $49.582^{b}$ & 6.680 & 9.9 & $\leq 0.001$ \\
\hline
\end{tabular}


relatively older imaging techniques and reported few differences between the patient and control groups and almost no difference between comorbid ADHD and CD with any of the two disorders alone [9, 37]. A relatively recent study replicated the same results with the exception of greater volume deficits in ADHD comorbid with disruptive disorders as compared to ADHD alone [41]. Another study indicated significantly smaller regional grey matter volumes in more extensive regions of the brains of youth with ADHD after controlling for the confounding effect of comorbid ODD and CD [51]. The most recent study which used structural imaging technique to assess youth with ODD and/or CD reported reduced grey matter volumes in temporal regions, particularly in girls but did not replicate previous findings of reduced grey matter volumes in the anterior insula, amygdala, and frontal cortex in youth with $\mathrm{CD}$ [43].

The reduction in both cortical and subcortical thickness in our sample of $\mathrm{CD}$ only youth is generally more profound and manifest than that previously reported in similar structural MRI studies [9, 13, 15, 16, 24, 34, 36, 42, 43]. This difference might be explained by the different inclusion criteria for recruited subjects in our sample. The above cited studies included youth with both oppositional defiant disorder (ODD) and CD. The mix of the two disorders most probably have produced a much milder form of disruptive behavior as compared to our sample which included only youth with $\mathrm{CD}$, mostly sever enough to be admitted to a child psychiatric inpatient unit.

With few exceptions, our results present a further support to the results reported by the recent meta-analysis performed by Noordermeer and colleagues [45]. Youth with $\mathrm{CD}$ in our sample showed lower cortical thicknesses and smaller volumes in some areas responsible for the so called "hot" executive functioning and reported to show smaller volumes in youth with disruptive behavior disorders regardless of comorbidity with ADHD in the cited meta-analysis, namely left precuneus, bilateral amygdale, and bilateral insula. Our results did not replicate the lower striatal volume reported in that meta-analysis but reported decreased cortical thickness in bilateral orbitofrontal gyri, another area that was also linked to hot executive functions $[47,50]$ but not found to be affected in the cited meta-analysis. On the other hand, Our results disagreed with the results of the metaanalysis regarding the affection of the main centers for "cool" executive functioning $[47,50]$, namely prefrontal cortex, cerebellar grey, and white matter, which were not judged to be affected in the meta-analysis. The prefrontal cortices did show reduction in thickness in $C D$ only youth but normal thickness in the CD + ADHD comorbid group while the cerebellar grey and white matter did show reduction in volumes in the two patient groups without significant differences between them. These disagreements might also be explained by the small number and sever $C D$ symptoms in our inpatient group. The collective sample of the meta-analysis which includes youth with ODD and CD with and without comorbid ADHD might be too diluted to detect the volumetric changes in prefrontal cortices present in $\mathrm{CD}$ only and not in comorbid youth.

In general, most of the brain areas showed volumetric reduction in our sample of severely ill conduct disordered youth but some of these areas, especially prefrontal cortices, might be spared in youth with both CD and ADHD. Given that the prefrontal cortices are known to be the main site of action for stimulant medications [27, 54], the well-known better response of the CD + ADHD youth on these medications as compared to the CD only youth $[48$, 51] may be considered as another support for that hypothesis. These results might be contradictory to the old notion that $\mathrm{CD}+\mathrm{ADHD}$ youth are more aggressive and more likely to develop an adult type antisocial personality when compared to CD only youth [22, 40, 46]. However, other studies, especially those exploring the electrophysiological differences such as skin conductance and heart rate, indicated no differences between CD + ADHD and CD only youth $[29-31,58]$. The only exception came from a study reporting that CD + ADHD boys showed greater HR acceleration following low provocation, but not high provocation, compared to CD only [57]. These contradicting results indicate the need for more studies aiming to understand $\mathrm{CD}$ subtypes based on ADHD symptoms and whether these subtypes represent homogeneous or heterogeneous groups of children [18].

\section{Conclusion}

In conclusion, our results support the notion that $\mathrm{CD}$ without comorbid ADHD might represent a severer form of the disorder than that associated with comorbid ADHD. Further studies are needed to evaluate the structural and functional alterations in the brains of conduct disordered youth and to explore the potential biological markers that might differentiate between $C D$ only and CD + ADHD youth.

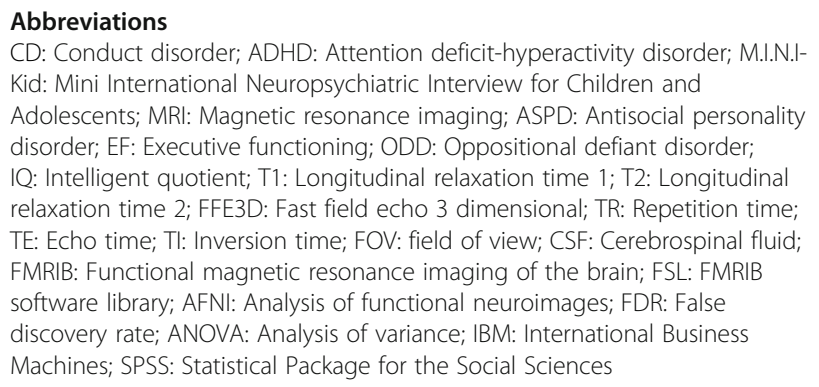

\section{Acknowledgements}

We would like to express our deep appreciation to Boris Birmaher, MD, Endowed Chair in Early Onset Bipolar Disease and Professor of Psychiatry, 
University of Pittsburgh, USA, for his revision and advice in writing this paper. Many thanks to Ahmed El-Zawawy, clinical psychologist, who did the psychometric evaluation for the recruited adolescents and to Maha and Marwa Salah, the two sister social workers for doing the socio-economic evaluation for participating families. Thanks are due also for the whole nursing and technician teams in the Child and Adolescent Psychiatry unit at Tanta Psychiatry and Neurology Center and the Department of Radiology in Tanta University Educational Hospital and for all participating families. This study was self-funded by the 1st and the 2 nd authors who paid the costs of imaging out of pocket. Subjects were willing to participate without any monetary compensation. All other authors declare no conflict of interest.

\section{Consent to publication}

Not applicable.

\section{Authors' contributions}

MS was responsible for the research idea and study design, choosing and confirming the diagnoses of the recruited subjects, and writing the manuscript. RE was responsible for supervising the process of brain imaging and writing the imaging parts of the manuscript. LS, LA, NE, and YM were responsible for preparing the protocol and requirements for ethical board approval and applying the psychometric tools. MR and MB were responsible for performing the statistical analysis using volumetric software. all authors have read and approved the manuscript for publication.

\section{Funding}

This study was self-funded. No funds were received.

\section{Availability of data and materials}

The dataset created and analyzed during the current study will be uploaded with manuscript in excel file format and will be available from the corresponding author on reasonable request.

\section{Ethics approval and consent to participate}

The study was approved by the Ethical Research Committee (ERC) of the Faculty of Medicine, Tanta University under the code 30383/06/15. All participants of the study gave their written consent to participate in the study.

\section{Competing interests}

The authors declare that they have no competing interests.

\section{Author details}

'Department of Psychiatry and Neurology, Faculty of Medicine, Tanta University, Elgiesh street, Tanta 31527, Egypt. ²Department of Radiology, Faculty of Medicine, Tanta University, Elgiesh street, Tanta 31527, Egypt.

${ }^{3}$ Tanta University Hospital, Elgiesh street, Tanta 31527, Egypt.

\section{Received: 7 October 2019 Accepted: 25 February 2020}

\section{Published online: 24 March 2020}

\section{Rerefences}

1. Abd El-Rakeep Ahmed El-Behary WAE-NH, Shawky OA, Aly AM (2004) The prevalence of conduct disorder in adolescent students in secondary schools in Assiut. Egypt J. Neurol. Psychiat. Neurosurg. 41(1):327-340

2. American Psychiatric Association, A (2013) Diagnostic and statistical manual of mental disorders: DSM-5. American Psychiatric Publishing, Arlington

3. Anderson NE, Kiehl KA (2013) Psychopathy: developmental perspectives and their implications for treatment. Restor Neurol Neurosci 32(1):103-117

4. Aoki Y, Inokuchi R, Nakao T, Yamasue H (2013) Neural bases of antisocial behavior: a voxel-based meta-analysis. Soc Cogn Affect Neurosci 9(8): 1223-1231

5. Beauchaine TP (2012) Physiological Markers of Emotional and Behavioral Dysregulation in Externalizing Psychopathology. Monogr Soc Res Child Dev 77(2):79-86

6. Blair RJ (2013) The neurobiology of psychopathic traits in youths. Nat Rev Neurosci 14(11):786-799

7. Blair RJ, Leibenluft E, Pine DS (2014) Conduct disorder and callousunemotional traits in youth. N Engl J Med 371(23):2207-2216
8. Burns GL, Walsh JA (2002) The influence of ADHD-hyperactivity/impulsivity symptoms on the development of oppositional defiant disorder symptoms in a 2-year longitudinal study. J Abnorm Child Psychol 30(3):245-256

9. Bussing R, Grudnik J, Mason D, Wasiak M, Leonard C (2002) ADHD and conduct disorder: an MRI study in a community sample. World J Biol Psychiatry 3(4):216-220

10. Connor D, Steeber J, McBurnett K (2010) A Review of Attention-Deficit/ Hyperactivity Disorder Complicated by Symptoms of Oppositional Defiant Disorder or Conduct Disorder. Journal of Developmental \& Behavioral Pediatrics (31):427-440

11. De Brito SA, Mechelli A, Wilke M, Laurens KR, Jones AP, Barker GJ, Hodgins S, Viding E (2009) Size matters: increased grey matter in boys with conduct problems and callous-unemotional traits. Brain 132(Pt 4):843-852

12. Deschamps P, Munsters N, Kenemans L, Schutter D, Matthys W (2014) Facial mimicry in 6-7 year old children with disruptive behavior disorder and ADHD. PLoS One 9(1):e84965

13. Sheehan DV, Sheehan KH, Shytle RD, Janavs J, Bannon Y, Rogers JE, Milo KM, Stock SL, Wilkinson B (2010a) Reliability and validity of the Mini International Neuropsychiatric Interview for Children and Adolescents (MINIKID). J Clin Psychiatry 71(3):313-326

14. Fahmy S, El-Sherbini AF (1983) Determining simple parameters for social classifications for health research. Bulletin of the High Institute of Public Health 13:95-108

15. Fahim C, He Y, Yoon U, Chen J, Evans A, Perusse D (2011) Neuroanatomy of childhood disruptive behavior disorders. Aggress Behav 37(4):326-337

16. Fairchild G, Passamonti L, Hurford G, Hagan CC, von dem Hagen EA, van Goozen SH, Goodyer IM, Calder AJ (2011) Brain structure abnormalities in early-onset and adolescent-onset conduct disorder. Am J Psychiatry 168(6): 624-633

17. Fanti KA (2013) Individual, social, and behavioral factors associated with cooccurring conduct problems and callous-unemotional traits. J Abnorm Child Psychol 41(5):811-824

18. Fanti KA (2016) Understanding heterogeneity in conduct disorder: A review of psychophysiological studies. Neurosci Biobehav Rev.

19. Fanti KA, Demetriou CA, Kimonis ER (2013) Variants of callous-unemotional conduct problems in a community sample of adolescents. J Youth Adolesc 42(7):964-979

20. Fanti KA, Henrich CC (2010) Trajectories of pure and co-occurring internalizing and externalizing problems from age 2 to age 12: findings from the National Institute of Child Health and Human Development Study of Early Child Care. Dev Psychol 46(5):1159-1175

21. Frick PJ, Dickens C (2006) Current perspectives on conduct disorder. Curr Psychiatry Rep 8(1):59-72

22. Frick PJ, Ellis M (1999) Callous-unemotional traits and subtypes of conduct disorder. Clin Child Fam Psychol Rev 2(3):149-168

23. Gao Y, Tuvblad C, Schell A, Baker L, Raine A (2015) Skin conductance fear conditioning impairments and aggression: a longitudinal study. Psychophysiology 52(2):288-295

24. Ghanem, S. (1998). Mini Kid schedule semi-structured interview., Institute of Psychiatry Ain Shams University.

25. Gilliom M, Shaw DS (2004) Codevelopment of externalizing and internalizing problems in early childhood. Dev Psychopathol 16(2):313-333

26. Hemphala M, Hodgins S (2014) Do psychopathic traits assessed in midadolescence predict mental health, psychosocial, and antisocial, including criminal outcomes, over the subsequent 5 years? Can J Psychiatry 59(1): 40-49

27. Hernaus D, Mehta MA (2016) Prefrontal cortex dopamine release measured in vivo with positron emission tomography: Implications for the stimulant paradigm. Neuroimage 142:663-667

28. Herpertz SC, Huebner T, Marx I, Vloet TD, Fink GR, Stoecker T, Shah NJ, Konrad K, Herpertz-Dahlmann B (2008) Emotional processing in male adolescents with childhood-onset conduct disorder. J Child Psychol Psychiatry 49(7):781-791

29. Herpertz SC, Mueller B, Qunaibi M, Lichterfeld C, Konrad K, HerpertzDahlmann B (2005) Response to emotional stimuli in boys with conduct disorder. Am J Psychiatry 162(6):1100-1107

30. Herpertz SC, Mueller B, Wenning B, Qunaibi M, Lichterfeld C, HerpertzDahlmann B (2003) Autonomic responses in boys with externalizing disorders. J Neural Transm (Vienna) 110(10):1181-1195

31. Herpertz SC, Sass H (2000) Emotional deficiency and psychopathy. Behav Sci Law 18(5):567-580 
32. Herpertz SC, Vloet T, Mueller B, Domes G, Willmes K, Herpertz-Dahlmann B (2007) Similar autonomic responsivity in boys with conduct disorder and their fathers. J Am Acad Child Adolesc Psychiatry 46(4):535-544

33. Herpertz SC, Wenning B, Mueller B, Qunaibi M, Sass H, Herpertz-Dahlmann B (2001) Psychophysiological responses in ADHD boys with and without conduct disorder: implications for adult antisocial behavior. J Am Acad Child Adolesc Psychiatry 40(10):1222-1230

34. Hoogman M, Bralten J, Hibar DP, Mennes M, Zwiers MP, Schweren LSJ, van Hulzen KJE, Medland SE, Shumskaya E, Jahanshad N, Zeeuw P, Szekely E, Sudre G, Wolfers T, Onnink AMH, Dammers JT, Mostert JC, Vives-Gilabert Y, Kohls G, Oberwelland E, Seitz J, Schulte-Ruther M, Ambrosino S, Doyle AE, Hovik MF, Dramsdahl M, Tamm L, van Erp TGM, Dale A, Schork A, Conzelmann A, Zierhut K, Baur R, McCarthy H, Yoncheva YN, Cubillo A Chantiluke K, Mehta MA, Paloyelis Y, Hohmann S, Baumeister S, Bramati I, Mattos P, Tovar-Moll F, Douglas P, Banaschewski T, Brandeis D, Kuntsi J, Asherson P, Rubia K, Kelly C, Martino AD, Milham MP, Castellanos FX, Frodl $T$, Zentis $M$, Lesch KP, Reif A, Pauli P, Jernigan TL, Haavik J, Plessen KJ, Lundervold AJ, Hugdahl K, Seidman LJ, Biederman J, Rommelse N, Heslenfeld DJ, Hartman CA, Hoekstra PJ, Oosterlaan J, Polier GV, Konrad K, Vilarroya O, Ramos-Quiroga JA, Soliva JC, Durston S, Buitelaar JK, Faraone SV, Shaw P, Thompson PM, Franke B (2017) Subcortical brain volume differences in participants with attention deficit hyperactivity disorder in children and adults: a cross-sectional mega-analysis. Lancet Psychiatry 4(4): 310-319

35. Huebner T, Vloet TD, Marx I, Konrad K, Fink GR, Herpertz SC, HerpertzDahlmann B (2008) Morphometric brain abnormalities in boys with conduct disorder. J Am Acad Child Adolesc Psychiatry 47(5):540-547

36. Hummer TA, Wang Y, Kronenberger WG, Dunn DW, Mathews VP (2014) The relationship of brain structure to age and executive functioning in adolescent disruptive behavior disorder. Psychiatry Res 231(3):210-217

37. Kruesi MJ, Casanova MF, Mannheim G, Johnson-Bilder A (2004) Reduced temporal lobe volume in early onset conduct disorder. Psychiatry Res 132(1):1-11

38. Loeber R, Burke J, Pardini DA (2009) Perspectives on oppositional defiant disorder, conduct disorder, and psychopathic features. J Child Psychol Psychiatry 50(1-2):133-142

39. Loeber R, Burke JD, Lahey BB, Winters A, Zera M (2000) Oppositional defiant and conduct disorder: a review of the past 10 years, part I. J Am Acad Child Adolesc Psychiatry 39(12):1468-1484

40. Lynam DR (1996) Early identification of chronic offenders: who is the fledgling psychopath? Psychol Bull 120(2):209-234

41. McAlonan GM, Cheung V, Cheung C, Chua SE, Murphy DG, Suckling J, Tai KS, Yip LK, Leung P, Ho TP (2007) Mapping brain structure in attention deficit-hyperactivity disorder: a voxel-based MRI study of regional grey and white matter volume. Psychiatry Res 154(2):171-180

42. Melika L (1998) The Stanford Binet Intelligence Scale. Arabic Examiner's Handbook, Cairo, Dar El Maref Publishing

43. Michalska KJ, Decety J, Zeffiro TA, Lahey BB (2015) Association of regional gray matter volumes in the brain with disruptive behavior disorders in male and female children. Neuroimage Clin 7:252-257

44. Moffitt TE (1993) Adolescence-limited and life-course-persistent antisocial behavior: a developmental taxonomy. Psychol Rev 100(4):674-701

45. Noordermeer SD, Luman M, Oosterlaan J (2016) A Systematic Review and Meta-analysis of Neuroimaging in Oppositional Defiant Disorder (ODD) and Conduct Disorder (CD) Taking Attention-Deficit Hyperactivity Disorder (ADHD) Into Account. Neuropsychol Rev 26(1):44-72

46. Patrick CJ (1994) Emotion and psychopathy: startling new insights. Psychophysiology 31(4):319-330

47. Prencipe A, Kesek A, Cohen J, Lamm C, Lewis MD, Zelazo PD (2011) Development of hot and cool executive function during the transition to adolescence. J Exp Child Psychol 108(3):621-637

48. Pringsheim T, Hirsch L, Gardner D, Gorman DA (2015) The pharmacological management of oppositional behaviour, conduct problems, and aggression in children and adolescents with attention-deficit hyperactivity disorder, oppositional defiant disorder, and conduct disorder: a systematic review and meta-analysis. Part 1: psychostimulants, alpha-2 agonists, and atomoxetine. Can J Psychiatry 60(2):42-51

49. Reuter M, Schmansky NJ, Rosas HD, Fischl B (2012) Within-subject template estimation for unbiased longitudinal image analysis. Neuroimage 61(4): $1402-1418$
50. Rubia K (2011) "Cool" inferior frontostriatal dysfunction in attention-deficit/ hyperactivity disorder versus "hot" ventromedial orbitofrontal-limbic dysfunction in conduct disorder: a review. Biol Psychiatry 69(12):e69-e87

51. Sasayama D, Hayashida A, Yamasue H, Harada Y, Kaneko T, Kasai K, Washizuka S, Amano N (2010) Neuroanatomical correlates of attentiondeficit-hyperactivity disorder accounting for comorbid oppositional defiant disorder and conduct disorder. Psychiatry Clin Neurosci 64(4):394-402

52. Schoorl J, Van Rijn S, De Wied M, Van Goozen SH, Swaab H (2016) Variability in emotional/behavioral problems in boys with oppositional defiant disorder or conduct disorder: the role of arousal. Eur Child Adolesc Psychiatry 25(8):821-830

53. Scott S, Knapp M, Henderson J, Maughan B (2001) Financial cost of social exclusion: follow up study of antisocial children into adulthood. BMJ 323(7306):191

54. Solanto MV (1998) Neuropsychopharmacological mechanisms of stimulant drug action in attention-deficit hyperactivity disorder: a review and integration. Behav Brain Res 94(1):127-152

55. Thorndike, R. L. H., E.P.; Sattler M. (1986). Stanford-Binet Intelligence Scale: Fourth Edition. Chicago, Riverside.

56. Wallace, G. L., S. F. White, B. Robustelli, S. Sinclair, S. Hwang, A. Martin and R. J. Blair (2014). "Cortical and subcortical abnormalities in youths with conduct disorder and elevated callous-unemotional traits." J Am Acad Child Adolesc Psychiatry 53(4): 456-465 e451.

57. Waschbusch DA, Pelham WE Jr, Jennings JR, Greiner AR, Tarter RE, Moss HB (2002) Reactive aggression in boys with disruptive behavior disorders: behavior, physiology, and affect. J Abnorm Child Psychol 30(6):641-656

58. Zahn TP, Kruesi MJ (1993) Autonomic activity in boys with disruptive behavior disorders. Psychophysiology 30(6):605-614

\section{Publisher's Note}

Springer Nature remains neutral with regard to jurisdictional claims in published maps and institutional affiliations.

\section{Submit your manuscript to a SpringerOpen ${ }^{\circ}$ journal and benefit from:}

- Convenient online submission

Rigorous peer review

- Open access: articles freely available online

High visibility within the field

- Retaining the copyright to your article

Submit your next manuscript at $>$ springeropen.com 